\title{
Poverty Trend and Infant Malnutrition in Rwanda
}

\author{
HARERIMANA Jean de Dieu*
}

University of Nairobi, School of Economics, Nairobi, Kenya

Received: April 2020

Accepted: June 2020

\section{A B S T R A C T}

Background and Objectives: A strong link between child malnutrition and poverty has been documented especially in developing countries. Considering one child under two year out of three in Rwanda suffers from some form of malnutrition, promoting community welfare seems to bring about beneficial outcomes in terms of reduction of malnutrition. This study aims to determine and estimate the risk factors associated with deprivation and infant malnutrition in Rwanda.

Materials and Methods: The methodology targeted mostly households with children under two years. Using two consecutive nationally representative population-based survey data of Rwanda, Demographic and Health Survey 2010/11 and 2014/15, the risk factors associated with the outcome were determined and using stepwise logistic regression analysis, the socioeconomic determinants were predicted.

Results: The findings were estimated from a sample of children under two years: 3,441 and 2,975 in Rwanda Demographic and Health Surveys 2010 and 2014/15. Households in the lowest wealth quintile were more likely to have children experiencing malnutrition $(\mathrm{OR}=1.61,95 \% \mathrm{CI}: 1.17-2.2, p<0.05$ in $2010 / 11$; $\mathrm{OR}=1.7,95 \%$ CI: $1.23-2.35$, $p<0.01$ in 2014/15) whereas deprivation was less likely to associate with malnutrition among children under two years (OR=0.53, 95\% CI: $0.35-0.8, p<0.001$ in 2014/15). Overall, the trend went down significantly with the slope of 0.1536 suggesting a decrease of deprivation between two surveys by 0.065 .

Conclusions: With the assumption of constancy of other factors, the trend of deprivation was significant to explain its association with infant malnutrition. Therefore, strengthening social protection interventions targeting the lowest wealth quintile category to afford food against price volatility are highly suggested.

Keywords: Dual burden, Food security, Deprivation, Stunting, Wasting, Underweight

\section{Introduction}

Recently, the global community has brought an attention to reduce malnutrition in children under two years as a significant risk factor for the child mortality, which is prevalent in developing countries $(1,2)$. To determine the factors affecting children malnutrition at the household level in Sub-Saharan Africa, it is likely to consider poverty situation as it is resulted from both market failure and household failure (3). It is evident from the recent literature that poverty in terms of the deprivation remains a conceptual causal factor for the optimal nutrition outcome during the first 1000-day of life (4-7).

Considering the millenium development goals (MDGs), the global situation on the malnutrition for children under five years of age resulted in different dimensions; the prevalence of stunting has declined gradually from $39.3 \%$ in 1990 but remained high universally with $22.2 \%$ against
$35.2 \%$ for low-income countries in 2017 , while $7.5 \%$ and $2.4 \%$ of children under 5 were estimated to have wasting and severe wasting, respectively. And lastly, globally the degree of overweight rose from 5.0 to $5.6 \%$ from 1990 up to $2017(8)$.

However, malnutrition in children under two years remains a threat in developing countries. And most specifically in Rwanda, where the malnutrition rates in children under five affected by stunting, wasting and underweight have been reported 38\%, 9\%, and $2 \%$ respectively, whereas acute malnutrition rate generally considered as severe wasting has reached to the relatively low level of 2\%(9). Recent data from the Rwanda Demographic Health Survey have shown that the national prevalence of stunting in children under five decreased 
from $51.7 \%$ to $38 \%$ in ten years between 2005 and 2015(9).

Several strategies have been employed to improve infant nutrition including cash transfer to vulnerable households, health and nutrition subsidies (e.g., provision of vitamin A and immunization) as well as other approaches linked to health promotion(10-13). These strategies usually make the members of the household, as a unit of analysis for the poverty incidence, interested to contribute to infant nutrition interventions(14). Though poverty may put infants at risk of poor health and nutrition, mother's education can be a strong predictor of her child's nutritional status $(15,16)$.

Global attempts have been made to address multidimensional issues of poverty that affect millions of children (17). Despite recent activities, the focus has primarily been on those who are currently poor rather than on those who are becoming impoverished $(18,19)$. It has been documented that modification of malnutrition prevalence necessitates scaling up health and nutrition interventions including interventions during the first thousand days of child's life (20).

Various risk factors of infant malnutrition are strongly associated with household deprivation. Moreover, modification of malnutrition remains unfinished in several sub-saharan countries if policymakers' knowledge of the risk factors is overlooked. The aim of this study was to assess risk factors of child's malnutrition associated with poverty in Rwanda.

\section{Materials and Methods}

We used data from Rwanda Demographic Household Survey (DHS), which included nationally and subnationally representative two-stage cluster samples and is conducted almost every 5years by the Rwanda Ministry of Health, National Institute of Statistics-Rwanda (NISR) and International Coach Federation (ICF). The surveys collect information from women aged 15-49 on their reproductive health histories, practices and desires; household composition; siblings' survival; and children's health and survival. The DHS birth history module included the date of the birth and death of each child born alive, and through the sibling module, the age and date of death for each biological sibling

\section{Study Design and Data Source}

The findings of the study are based on Rwanda Demographic and Health Survey (RDHS). A secondary data conducted almost every five years by National Institute of Statistics of Rwanda (NISR) and Ministry of Health (MOH)/Rwanda with support from ICF International. DHS included a nationally and sub-nationally representative two-stage cluster sampling of villages and households with stratification by all Rwanda Districts and sample size might slightly change for each survey wave (see Table 1).

Furthermore, RDHS 2010 and 2014/2015 comprise exhaustive information on infant and child anthropometric information for more than 3,441 and 2,975 children undertwo years from the survey waves, respectively. The analysis of infant nutritional status using demographic information, nutrition deprivation and dynamics of poverty explain the behavioral impact and provides the expected degree of infant malnutrition.

\section{Definition of the Variables}

Outcome variables: Infant malnutrition is defined in this study as any child under two years characterized with suboptimal nutritional indicator as an outcome. It is measured from DHS, referring to the WHO growth standards and this helps to calculate the Z-score with stored and referenced the median of the 2006 WHO growth reference population that considers specific characteristics (WHO Anthro and Macros https://www.who.int/childgrowth/software/en/ ) including gender, age of the specific children targeted group, weight/height and oedema. During the estimation, the infant malnutrition measured 1 or 0 (healthy children) and in all tables, we reported value of concern, which infant malnutrition.

Table 1. Rwanda Demographic and Health Survey: Sample Size

\begin{tabular}{lcc}
\hline Respondents & RDHS-2010/11 & RDHS-2014/15 \\
\hline Household & 12,540 & 12,699 \\
Female (all women aged: 15-49 years) & 13,671 & 13,497 \\
Male (all men aged: 15-59 years) & 6,329 & 6,217 \\
\hline Fieldwork Period & Sept 2010 - March 2011 & Nov2014 - April 2015 \\
\hline
\end{tabular}




\section{Independent variable}

Deprivation is defined based on MDG indicators at the time of surveys. The variable includes all households with children two years falling under minimum cut-off of each indicator and considers essential living standards (i.e. access to improved water, sanitation, improved cooking fuel, electricity, floor and households' assets) $(21,22)$.

Following Oxford Poverty \& Human Development Initiative (OPHI) on the measurement of the Global Multidimensional Poverty Index (23), we retrieved living standards dimensions to reflect the important factor determining the welfare of children under two years, where most households prefer to invest on non-food items in developing countries (24).

In analyses deprivation was considered as a binary with 1 if household is deprived and 0 otherwise. By definition, long-term accumulated effect of deprivation results in poverty, when a household fail to secure basics of living standards. Hence, the study focuses on the magnitude of poverty in terms of deprivation in presence of children under two years.

\section{Control variables}

Demographic characteristics included parent characteristics and the highest number of years of education of the woman. Occupation of the woman and area of residence were also considered. Children category, such as age (measure in months), sex ( 1 if a boy and 0 for girls) and low birth weight defined giving birth to a child with less than 2500 grams at birth. Further to household characteristics, the study preserved the nature of household wealth category as described in DHS, we categorized the variable into binary, 1 if household is located in the $20 \%$ of the lowest wealth category (least poor and poorer) and if the household is located in middle, richer and richest wealth category.

\section{Statistical analyses}

Descriptive statistics was used to compare the covariate balance between determinants of infant malnutrition in Rwanda using DHS 2010 and 2014/15. The demographic and socio-economic factors associated with infant malnutrition were identified in Rwanda DHS 2010 and 2014/15. The analysis was used percentages and Chisquare tests to validate the bivariate association with demographic, social and economic variables.

Finally, we used manual backward stepwise logistic regression, first removing variables that were least associated with infant malnutrition and retaining those variables that were associated with infant malnutrition ( $\mathrm{p}<$ 0.05). Separate models were fit for 2010 and 2014/15 using the reduced set of variables available in 2010, and for
2014/15. The analysis was carried out by Stata version 15 using survey commands to apply sampling probability weights, accounting for clustering and stratification in the sample design, and perform subpopulation analysis in marriage only.

\section{Results}

In this study, the results were reported from the sample of 2,882 and 2,834 of children under two years (infant) from the household interviewed in Rwanda DHS 2010 and 2014/2015, respectively. For the children-related factors, the following variables were significantly associated with infant malnutrition: the prevalence of malnutrition in both DHS surveys (2010 vs 2014/15) for sex of an infant ( $p<$ 0.01 ) depicts that: infant sex: $38.6 \%$ vs $37.6 \%$ were boys and girls were $24.9 \%$ vs $20.5 \%$, infant's age varied according to the age categories where less than 6 months (15.4\% vs $10.4 \%$ ), 6-9 months (23.6\% vs $19 \%)$, $10-17$ months $(29.9 \%$ vs $32.2 \%)$ and $18-24$ months (52\% vs $48.9 \%)$.

However, the low birth weight was only significantly associated with infant malnutrition only in 2014/15, 53.5\% of children had low birth weight, and $36.4 \%$ of diarrhea cases $(\mathrm{p}<0.05)$, were associated with infant malnutrition (Table 2).

The characteristics of parents, mother's age was significantly associated with infant malnutrition both in 2010 ( $\mathrm{p}<0.1$ ) and 2014/15 ( $\mathrm{p}<0.05$ ), from 15-24 years (29.2\% vs $21.4 \%), 25-34$ years $(28.8 \%$ vs $30.9 \%), 35-44$ years $(42.1 \%$ vs $32.7 \%)$ and 45 +years $(32.7 \%$ vs $30.7 \%)$, from father's age ( $\mathrm{p}<0.05$ ), only DHS 2010 findings showed an association with infant malnutrition in Rwanda, 18-24 years $(30.4 \%), 25-34$ years $(28.1 \%), 35-44$ years (36.8\%) and 45-59years (42.2\%) (Table 2). Moreover, the mother's education was significantly associated with the infant malnutrition where the rates for mother's education with less than secondary education were $33.4 \%$ vs $31.2 \%$ and for those with secondary and higher education were $14.5 \%$ vs $17.8 \%$, in DHS 2010 and 2014/15, respectively.

Finally, parent's occupation was significantly associated with infant malnutrition in DHS 2014/15 but not with mother's occupation in 2010. Furthermore, the findings showed that deprivation $(25.6 \%)$ was significantly associated with the infant malnutrition in 2014/15. Nevertheless, the household located in the lowest wealth quintile had a malnourished infant in both DHS surveys (38.4\% and 36.5\%). Finally, living in a rural area significantly associated with infant malnutrition $(32.7 \%$ in 2010 and $31.3 \%$ in 2014/15) and an urban area associated with infant malnutrition $(20.1 \%$ in 2010 and $16.7 \%$ in 2014/15). 
HARERIMANA Jean de Dieu: Poverty trend and infant malnutrition in Rwanda

Table 2. Bivariate associations between demographic, social, and economic variables and Infant Malnutrition, Rwanda 2010 and $2014 / 15$

\begin{tabular}{|c|c|c|c|c|c|c|}
\hline & \multirow{2}{*}{\multicolumn{3}{|c|}{$\frac{\text { DHS-2010 }(\mathrm{N}=2,882)}{\text { Malnourished Infant }}$}} & \multirow{2}{*}{\multicolumn{3}{|c|}{$\frac{\text { DHS-2014/15 }(\mathrm{N}=2,834)}{\text { Malnourished Infant }}$}} \\
\hline & & & & & & \\
\hline & $\%$ & $95 \% \mathrm{CI}$ & P-val & $\%$ & $95 \% \mathrm{CI}$ & P-val \\
\hline Infant's age & & & $<0.01$ & & & $<0.01$ \\
\hline$<6 \quad$ Months & 15.4 & $10.5-21.9$ & & 10.4 & $6.3-16.6$ & \\
\hline 6-9 Months & 23.6 & $17.1-31.6$ & & 19 & $13.5-25.9$ & \\
\hline 10-17 Months & 29.9 & $24.1-36.3$ & & 31.2 & $25.5-37.5$ & \\
\hline 18-24 Months & 52 & $44.2-59.7$ & & 48.9 & $41.2-56.6$ & \\
\hline Infant Sex & & & $<0.01$ & & & $<0.01$ \\
\hline Girls & 24.9 & 20.9-29.4 & & 20.5 & $16.7-25.1$ & \\
\hline Boys & 38.6 & $33.1-44.3$ & & 37.6 & $32.3-43.3$ & \\
\hline Low birth weight & & & 0.239 & & & $<0.01$ \\
\hline No & 30.7 & $27.2-34.5$ & & 27.7 & $24.3-31.4$ & \\
\hline Yes & 40.7 & $26.4-56.7$ & & 53.5 & $37.3-69.1$ & \\
\hline Diarrhea & & & 0.650 & & & 0.039 \\
\hline No & 30.8 & $27.0-35.0$ & & 27 & $23.4-30.9$ & \\
\hline Yes & 32.9 & $25.4-41.4$ & & 36.4 & $28.1-45.6$ & \\
\hline Wife's age & & & 0.073 & & & 0.0107 \\
\hline 15-24 Years & 29.2 & $23.5-35.7$ & & 21.4 & $15.7-28.4$ & \\
\hline 25-34 Years & 28.8 & $24.3-33.7$ & & 30.9 & $26.4-35.8$ & \\
\hline 35-44 Years & 42.1 & $33.2-51.6$ & & 32.7 & $25.8-40.3$ & \\
\hline $45+$ Years & 32.7 & $10.9-66.0$ & & 30.7 & $6.9-72.6$ & \\
\hline Educated Mother & & & $<0.01$ & & & $<0.01$ \\
\hline$<$ Secondary & 33.4 & 29.6-37.4 & & 31.2 & $27.4-35.1$ & \\
\hline Secondary + & 14.5 & $8.3-24.0$ & & 17.8 & $11.7-26.0$ & \\
\hline Woman Occupation & & & 0.234 & & & 0.022 \\
\hline Unemployed & 24.9 & $17.2-34.5$ & & 23.6 & $13.6-37.6$ & \\
\hline Employed & 27.7 & $19.6-37.5$ & & 22.3 & $16.9-28.7$ & \\
\hline Self-Employed & 32.9 & $28.7-37.4$ & & 32.8 & $28.2-37.6$ & \\
\hline Husband's age & & & 0.029 & & & 0.918 \\
\hline 18-24 Years & 30.7 & 21.4-41.8 & & 28.1 & $17.3-42.2$ & \\
\hline 25-34 Years & 28.1 & $23.8-32.9$ & & 28.8 & $24.4-33.7$ & \\
\hline 35-44 Years & 36.8 & $29.4-44.8$ & & 27.6 & $21.7-34.3$ & \\
\hline $45+$ Years & 42.2 & $29.6-55.8$ & & 32.7 & $22.2-45.3$ & \\
\hline Husband Occupation & & & 0.033 & & & $<0.01$ \\
\hline Unemployed & 11.3 & $1.5-51.8$ & & 86.7 & $45.0-98.1$ & \\
\hline Employed & 25.6 & 20.4-31.6 & & 23.4 & $19.3-28.0$ & \\
\hline Self-Employed & 34 & $29.5-38.7$ & & 34.8 & $29.6-40.3$ & \\
\hline Lowest Wealth Quintile & & & $<0.01$ & & & $<0.01$ \\
\hline No & 26.1 & $22.0-30.7$ & & 23.3 & $19.4-27.8$ & \\
\hline Yes & 38.4 & $32.8-44.4$ & & 36.5 & $31.2-42.2$ & \\
\hline Deprivation & & & 0.169 & & & $<0.01$ \\
\hline No & 35.4 & $28.6-42.9$ & & 38.3 & $31.1-46.0$ & \\
\hline Yes & 29.8 & $25.9-34.1$ & & 25.6 & $22.0-29.6$ & \\
\hline Residence & & & 0.022 & & & $<0.01$ \\
\hline Urban & 20.1 & $12.7-30.2$ & & 16.7 & $11.9-22.9$ & \\
\hline Rural & 32.7 & $29.0-36.7$ & & 31.3 & $27.4-35.5$ & \\
\hline Household members & & & 0.467 & & & 0.157 \\
\hline 1-3 Members & 28.7 & $22.7-35.5$ & & 28.1 & $21.7-35.5$ & \\
\hline 4-8 Members & 31.8 & $27.6-36.4$ & & 29.9 & $25.9-34.3$ & \\
\hline 9+ Members & 38.8 & $24.1-55.8$ & & 13.8 & $6.9-25.6$ & \\
\hline
\end{tabular}

Multivariate analysis, the full logistic regression model (Full Model) (Table 3), revealed that the infants were more likely to experience malnutrition during 6 to 9 months (Odds Ratio $(\mathrm{OR})=2.33,95 \%$ Confidence Interval $(\mathrm{CI})$ : $1.29-4.2, p<0.05)$ only for $2014 / 15,10$ to 17 months $(\mathrm{OR}=$ 2.33, 95\% CI: $1.35-4.01, p<0.001$ in 2010/11), and for 2014/15, (OR $=4.57,95 \% \mathrm{CI}: 2.4-8.54, p<0.01)$ and 18 to 24 months $(\mathrm{OR}=6.17,95 \%$ CI: 3.49-10.9, $p<0.001$ in 2010/11), and for 2014/15, (OR = 8.93, 95\% CI: 4.69-17, $p<0.01)$.
Being a boy showed an increased odds for experiencing malnutrition $(\mathrm{OR}=1.83,95 \% \mathrm{CI}: 1.3-2.59, p<0.01$ in 2010/11), and (OR = 2.33, 95\% CI: 1.64-3.29, $p<0.01)$, and low child weight at birth $(\mathrm{OR}=3.92,95 \% \mathrm{CI}: 1.76$ $8.71, p<0.01)$ in the DHS-2014/15. Parents characteristics, including lower risk among educated mothers with high school or higher $(\mathrm{OR}=0.43,95 \%$ CI $0.2-0.99, \mathrm{p}<0.05)$ for the DHS-2010/11, employed father $(\mathrm{OR}=0.05,95 \% \mathrm{CI}$ $0.01-0.36, \mathrm{p}<0.05)$ and self-employed $(\mathrm{OR}=0.06,95 \% \mathrm{CI}$ $0.01-0.47, \mathrm{p}<0.05)$ for the DHS-2014/15 were associated with infant malnutrition. 
HARERIMANA Jean de Dieu: Poverty trend and infant malnutrition in Rwanda

Table 3. Multivariable analysis of risk factors associated with Infant malnutrition in Rwanda, DHS 2010 and $2014 / 15$

\begin{tabular}{|c|c|c|c|c|c|c|c|c|}
\hline & \multicolumn{4}{|c|}{ DHS-2010/11 $(\mathrm{N}=3,441)$} & \multicolumn{4}{|c|}{ DHS-2014/15 $(\mathrm{N}=2,975)$} \\
\hline & \multicolumn{2}{|c|}{ Full Model } & \multicolumn{2}{|c|}{ Reduced Model } & \multicolumn{2}{|c|}{ Full Model } & \multicolumn{2}{|c|}{ Reduced Model } \\
\hline & OR & $95 \% \mathrm{CI}$ & OR & $95 \% \mathrm{CI}$ & OR & $95 \% \mathrm{CI}$ & OR & $95 \% \mathrm{CI}$ \\
\hline \multicolumn{9}{|l|}{ Infant's age } \\
\hline$<6 \quad$ Months & & & & & & & & \\
\hline 6-9 Months & 1.5 & $0.81-2.77$ & 1.44 & $0.82-2.5$ & $2.33^{\mathrm{b}}$ & $1.29-4.2$ & $2.36^{\mathrm{a}}$ & $1.33-4.2$ \\
\hline 10-17 Months & $2.33^{\mathrm{a}}$ & $1.35-4.01$ & $2.27^{\mathrm{a}}$ & $1.4-3.68$ & $4.57^{\mathrm{a}}$ & $2.4-8.54$ & $4.71^{\mathrm{a}}$ & $2.57-8.65$ \\
\hline 18-24 Months & $6.17^{\mathrm{a}}$ & $3.49-10.9$ & $5.08^{\mathrm{a}}$ & $3.03-8.5$ & $8.93^{\mathrm{a}}$ & $4.69-17$ & $9.26^{\mathrm{a}}$ & $4.96-17.2$ \\
\hline \multicolumn{9}{|l|}{ Infant Sex } \\
\hline \multicolumn{9}{|l|}{ Girls } \\
\hline Boys & $1.83^{\mathrm{a}}$ & $1.3-2.59$ & 1.8 & $1.3-2.47$ & $2.33^{\mathrm{a}}$ & $1.64-3.29$ & $2.24^{\mathrm{a}}$ & $1.59-3.16$ \\
\hline \multicolumn{9}{|c|}{ Low Birth Weight } \\
\hline Yes & & & & & $3.92^{\mathrm{a}}$ & $1.76-8.71$ & $3.77^{\mathrm{b}}$ & $1.66-8.58$ \\
\hline \multicolumn{9}{|l|}{ Wife's age } \\
\hline \multicolumn{9}{|l|}{$15-24$ Years } \\
\hline $25-34$ Years & 0.97 & $0.63-1.49$ & & & 1.37 & $0.89-2.1$ & & \\
\hline 35-44 Years & 1.55 & $0.79-3.02$ & & & 1.27 & $0.75-2.15$ & & \\
\hline $45+$ Years & 0.5 & $0.11-2.34$ & & & 0.53 & $0.08-3.56$ & & \\
\hline \multicolumn{9}{|c|}{ Educated Mother } \\
\hline Secondary + & $0.43^{\mathrm{b}}$ & $0.2-0.92$ & $0.45^{\mathrm{b}}$ & $0.24-0.86$ & 0.91 & $0.51-1.63$ & & \\
\hline \multicolumn{9}{|c|}{ Woman Occupation } \\
\hline Employed & 2.65 & $0.26-26.6$ & & & 0.58 & $0.27-1.25$ & & \\
\hline Self-Employed & 2.86 & $0.29-28.7$ & & & 0.74 & $0.34-1.61$ & & \\
\hline \multicolumn{9}{|l|}{ Husband's age } \\
\hline \multicolumn{9}{|l|}{$18-24$} \\
\hline $25-34$ & 0.79 & $0.43-1.43$ & & & & & & \\
\hline $35-44$ & 0.94 & $0.47-1.89$ & & & & & & \\
\hline $45-59$ & 1.03 & $0.44-2.42$ & & & & & & \\
\hline \multicolumn{9}{|c|}{$\begin{array}{l}\text { Husband Occupation } \\
\text { Unemployed }\end{array}$} \\
\hline Employed & 14.8 & $1.6-137.5$ & & & $0.05^{\mathrm{b}}$ & $0.01-0.36$ & $0.04^{b}$ & $0.01-0.27$ \\
\hline Self-Employed & 20.9 & $2.2-194.1$ & & & $0.06^{\mathrm{b}}$ & $0.01-0.47$ & $0.06^{\mathrm{b}}$ & $0.01-04$ \\
\hline \multicolumn{9}{|c|}{ Lowest Wealth Quintile } \\
\hline Yes & $1.69^{\mathrm{a}}$ & $1.15-2.48$ & $1.61^{\mathrm{b}}$ & $1.17-2.2$ & $1.68^{\mathrm{a}}$ & $1.18-2.38$ & $1.7^{\mathrm{a}}$ & $1.23-2.35$ \\
\hline \multicolumn{9}{|l|}{ Deprivation } \\
\hline Yes & 0.8 & $0.54-1.19$ & 0.86 & $0.6-1.23$ & $0.55^{\mathrm{b}}$ & $0.37-0.83$ & $0.53^{\mathrm{b}}$ & $0.35-0.8$ \\
\hline \multicolumn{9}{|l|}{ Residence } \\
\hline Rural & 1.12 & $0.61-2.03$ & & & 1.24 & $0.71-2.15$ & & \\
\hline
\end{tabular}

As for the factors related to the household characteristics, being in the lowest wealth quintile was more likely to have children experiencing malnutrition $(\mathrm{OR}=1.69,95 \%$ CI: 1.15-2.48, $p<0.01$ in 2010/11; OR= 1.68, 95\% CI: 1.18-2.38, $p<0.01$ in 2014/15) and thus, deprivation was less likely to associate with malnutrition among children under two years $(\mathrm{OR}=0.55,95 \% \mathrm{CI}$ : 0.37 $0.83, p<0.001$ in 2014/15).

In the reduced logistic regression model (Reduced Model) obtained after applying the stepwise process, factors associated with infant malnutrition were: children aged 6-9 months $(\mathrm{OR}=2.36,95 \%$ CI $1.33-4.2, p<0.01)$ in 2014/15, and 10-17 months $(\mathrm{OR}=2.27,95 \% \mathrm{CI}: 1.4-3.68$, $p<0.01$ in 2010/11; OR= 4.71, 95\% CI: 2.57-8.65, $p<0.01$ in 2014/15), and 18-24months $(\mathrm{OR}=5.08,95 \%$ CI: $3.03-$ $8.5, p<0.01$ in 2010/11; OR=9.26, 95\% CI: 4.96-17.2, $p<0.01$ in 2014/15). There was a higher risk among boys for being malnourished in DHS-2014/15, (OR=2.24, 95\% CI 1.59-3.16, $p<0.01)$ and low child weight at birth $(\mathrm{OR}=3.77, \quad 95 \% \quad \mathrm{CI} \quad 1.66-8.58, \quad \mathrm{p}<0.05)$. Parents characteristics, including lower risk among employed father $(\mathrm{OR}=0.04,95 \%$ CI $0.01-0.27, p<0.05)$ and selfemployed $(\mathrm{OR}=0.06,95 \%$ CI $0.01-0.4, p<0.05)$ for the DHS-2014/15.

The logistic regression was used to determine the association between infant malnutrition and its risk factors since the factors are likely to become a non-linear model and helps to determine the direction of each period. For 
comparison, and drawing the variation between DHS2010/11 and DHS-2014/15, the marginal effects obtained from the reduced model (final logistic model). It draws a conclusion on both magnitude and significance of the point estimates are quite different from those obtained for the full model.

Table 4 shows the predicted probability of having malnourished children under two years in Rwanda in 2010/11 and 2014/15 which was 0.277 and 0.251, respectively. The findings also demonstrate that infant's age had a significant positive association with infant malnutrition in both surveys so. that one more month for the children between 6 and 9 months increased the likelihood the probability of being malnourished by 0.17 points in 2014/15and in children aged between 10-17 months, one more month increased by 0.17 and 0.31 points, in 2010/11 and 2014/15, respectively. In children aged between 18-24 months, one more month increased the likelihood to have malnutrition by 0.35 and 0.47 points for 2010/11 and 2014/15, respectively.

Also, having more children, and having a boy among children less than two years increased the probability of infant malnutrition by 0.12 and 0.15 . Being in a poor household (based on the current wealth category in Rwanda), increased the likelihood for having malnourished infant by 0.096 and 0.12 for both 2010/11 and 2014/15, respectively.

Surprisingly, the more the household became deprived from an important resource (i.e. investing in education, access to improved water, electricity, and improved sanitation) decreased the probability of having a malnourished child by 0.03 and 0.13 in 2010/11 and $2014 / 15$. Finally, the more husband had an access to the certain wage decreased the probability of having a malnourished child by 0.56 and when self-employed by 0.48 .

Table 5 highlights that the evolution in the distribution of infant malnutrition in the household observed in the determinants for both DHS-2010/11 and DHS-2014/15 for reasonable comparison. A slight increase in infant malnutrition observed with infant's age, lowest wealth quintile and husband's occupation with $0.113,0.082$ and 0.054 , respectively, while a decrease observed with deprivation between two surveys by 0.065 . Overall, the trend went down significantly with the slope of 0.1536 .

Table 4. Marginal effects for the risk factors associated with Infant malnutrition in Rwanda, DHS 2010 and 2014/15

\begin{tabular}{|c|c|c|c|c|c|c|}
\hline & \multicolumn{3}{|c|}{ RDHS-2010/11 } & \multicolumn{3}{|c|}{ RDHS-2014/14 } \\
\hline & Estimate & Mean & $95 \% \mathrm{CI}$ & Estimate & Mean & $95 \% \mathrm{CI}$ \\
\hline Infant malnutrition & 0.277 & & & 0.251 & & \\
\hline \multicolumn{7}{|l|}{ Infant's age } \\
\hline$<6 \quad$ Months & & & & & & \\
\hline 6-9 Months & 0.07 & 0.16 & $-.04-0.19$ & $0.17^{\mathrm{b}}$ & 0.21 & $0.052-0.3$ \\
\hline 10-17 Months & $0.17^{\mathrm{a}}$ & 0.34 & $0.07-0.27$ & $0.31^{\mathrm{a}}$ & 0.35 & $0.435-0.35$ \\
\hline 18-24 Months & $0.35^{\mathrm{a}}$ & 0.26 & $0.24-0.47$ & $0.47^{\mathrm{a}}$ & 0.25 & $0.35-0.6$ \\
\hline Infant Sex (Boys) & $0.12^{\mathrm{a}}$ & 0.48 & $0.05-0.18$ & $0.15^{\mathrm{a}}$ & 0.49 & $0.21-0.49$ \\
\hline Low birth weight & & & & $0.3^{\mathrm{b}}$ & 0.04 & $0.103-0.5$ \\
\hline Lowest wealth Quintile & $0.096^{\mathrm{a}}$ & 0.43 & $0.032-0.16$ & $0.1^{\mathrm{a}}$ & 0.44 & $0.039-0.16$ \\
\hline Deprivation & -0.03 & 0.73 & $-0.1-0.04$ & $-0.13^{b}$ & 0.75 & $-0.21-0.75$ \\
\hline \multicolumn{7}{|l|}{ Husband Occupation } \\
\hline \multicolumn{7}{|l|}{ Unemployed } \\
\hline Employed & & & & $-0.56^{\mathrm{a}}$ & 0.52 & $-0.85--0.28$ \\
\hline Self-Employed & & & & $-0.48^{\mathrm{a}}$ & 0.46 & $-0.48--0.2$ \\
\hline
\end{tabular}

${ }^{\mathrm{a}}<0.001,{ }^{\mathrm{b}}<0.05$

Table 5. Poverty Trend analysis on infant malnutrition between 2010/11 and 2014/15

\begin{tabular}{|c|c|c|}
\hline Parameters & Variation & $95 \% \mathrm{CI}$ \\
\hline $\begin{array}{l}\text { Infant's age } \\
\text { Deprivation } \\
\text { Lowest wealth quintile } \\
\text { Husband Occupation }\end{array}$ & $\begin{array}{c}0.113^{\mathrm{a}} \\
-0.065^{\mathrm{a}} \\
0.082^{\mathrm{a}} \\
0.054^{\mathrm{a}}\end{array}$ & $\begin{array}{c}0.103-0.122 \\
-0.09--0.04 \\
0.06-0.075 \\
0.034-0.074\end{array}$ \\
\hline $\begin{array}{l}\text { Variance-weighted leas } \\
\text { Trend analysis for prop }\end{array}$ & $\begin{array}{l}0.001 \\
\text { Prob>chi2: }<0.001\end{array}$ & \\
\hline
\end{tabular}




\section{Discussion}

Findings from this study revealed that the degree of malnutrition in Rwanda had been reduced for each of the anthropometric indicators for the period between 2010 and 2014/2015. But it remained high for the one dimension which is chronic malnutrition for the children between 12 to 23 months, persisted at $52.05 \%$ and $43.07 \%$ for 2010 and 2014 respectively.

The identified risk factors associated with infant malnutrition in 2010 and 2014/15 surveys were the infant's age, several household members, lowest wealth quintile (poorest) household and educated mother. Moreover, in 2014/2015, being male (boys), low birth weight and husband's occupation were among factors affecting infant malnutrition. Born in the poorest household (lowest quintile) increased the likelihood of having malnutrition among children under two years probably due to less sharing of nutritious foods $(25,26)$.

Conversely, the poverty in terms of living standards of deprived household, such as assets, sanitation, electricity, and access to clean water did not increase the odds for having malnourished children, in both surveys. The previous studies showed that poverty and deprivation in low-income households do not solely define their wellbeing through income and consumption $(27,28)$ because their wealth is spent on food materials/intake and expenditure share $(25,26,28)$.

Moreover, infant characteristics, low birth weight (less than 2500 grams) increased the odds of being malnourished compared to the previous survey, boys experienced malnutrition compared to their peer group of girls. Also, as the infants grow up, the odds of being malnourished increases too. It has been suggested that the nutrient intake by an infant relies on the size at birth for storing the calories reserves. The low birth weight of a child necessitates extra maternal care time and special treatment for providing adequate amounts of energy and nutrients $(33,34)$. Otherwise, the likelihood of experiencing malnutrition increases as the affected child grows up.

In this study, husband employment was inversely associated with infant malnutrition(31), the more husband had an access to the certain wage decreased the probability of having a malnourished child by 0.56 and when selfemployed by 0.48 . The findings also showed that there was a significant decrease of having a malnourished child when household became less deprived. This implies that the investment preferences among household members to improve living standards were significantly associated with infant malnutrition in Rwanda.

\section{Conclusion}

Overall, this study showed that poverty trend was significantly related to infant malnutrition with the assumption that other factors were constant during two DHS surveys in Rwanda. Furthermore, lowest wealth quintile households associated with infant malnutrition. A report on poverty in Rwanda showed that the proportion of households facing some sorts of financial shocks has increased to $38 \%$ including $8 \%$ who experienced increased food price shock(32). Hence, the food expenditure share has risen to the extent that the household reduces the required quantity and quality of food intake as well as its frequency.

Therefore, there is a need to initiate strong social protective interventions that can help the lowest wealth quintile household to afford food against its volatility. Moreover, a poverty dynamics analysis using experimental methods is highly recommended for future studies to identify reasons why poverty reduction does not associate with or reflect in a decrease of malnutrition cases in Rwanda.

\section{Financial disclosure}

The author declared no financial interest.

\section{Funding/Support}

There are no financial support of the research.

\section{References}

1. Black RE, Morris SS, Bryce J. Where and why are 10 million children dying every year? Lancet. 2003;361(9376):2226-34.

2. Rice AL, Sacco L, Hyder A, Black RE. Malnutrition as an underlying cause of childhood deaths associated with infectious diseases in developing countries. Bull World Health Organ. 2000;78(10):1207-21.

3. Dalton PS, Ghosal S, Mani A. Poverty and Aspirations Failure. Econ J. 2016;126(590):165-88.

4. Bhatia J, Bhutta Z., Kalhan S. Maternal and Child Nutrition: The First 1,000 Days. Indian J Med Res. 2015;142(2):231-2.

5. Bourke CD, Berkley JA, Prendergast AJ. Immune Dysfunction as a Cause and Consequence of Malnutrition. Trends Immunol. 2016;37(6):386-98.

6. de Onis M, Branca F. Childhood stunting: A global perspective. Matern Child Nutr. 2016;12 Suppl 1(Suppl 1):12-26.

7. Shimpton R, Rokx C. The Double Burden of Malnutrition: A review of global evidence. Health, Nutrition and Population Discussion Paper.The World Bank. 2012.

8. UNICEF, WHO, Bank W. Levels and trends in child malnutrition: Key findings of the 2018 Edition of the Joint Child Malnutrition Estimates. Joint child malnutrition estimates - Levels and trends. Geneva: World Health Organization; 2018.

9. NISR, MOH-Rwanda, ICF International. Rwanda Demographic and Health Survey, 2014-2015. ICF International. 2016.

10. Adato M, Bassett L. Social protection to support vulnerable children and families: The potential of cash transfers to 
protect education, health and nutrition. AIDS Care. 2009;21(S1):60-75.

11. Haushofer J, Shapiro J. The short-term impact of unconditional cash transfers to the poor: Experimental evidence from kenya. Q J Econ. 2016;131(4):1973-2042.

12. Jensen RT, Miller NH. Do consumer price subsidies really improve nutrition? Rev Econ Stat. 2011;93(4):1205-23.

13. Kaushal N, Muchomba FM. How Consumer Price Subsidies affect Nutrition. World Dev. 2015;74(C):25-42.

14. Crooks DL. Child growth and nutritional status in a highpoverty community in eastern Kentucky. Am J Phys Anthropol. 1999;109(1):129-42.

15. Abuya BA, Ciera J, Kimani-Murage E. Effect of mother's education on child's nutritional status in the slums of Nairobi. BMC Pediatr. 2012;12(1):80.

16. Christian P, Mullany LC, Hurley KM, Katz J, Black RE. Nutrition and maternal, neonatal, and child health. Semin Perinatol. 2015;39(5):361-72.

17. Bhutta ZA, Das JK, Rizvi A, Gaffey MF, Walker N, Horton $\mathrm{S}$, et al. Evidence-based interventions for improvement of maternal and child nutrition: What can be done and at what cost? The Lancet. 2013.

18. Kraay A, McKenzie D. Do Poverty Traps Exist? Assessing the Evidence. J Econ Perspect. 2014;

19. Duclos JY, Araar A, Giles J. Chronic and transient poverty: Measurement and estimation, with evidence from China. J Dev Econ. 2010;

20. Mahadevan R, Hoang V. Is There a Link Between Poverty and Food Security? Soc Indic Res. 2016;

21. Ward PS. Transient Poverty, Poverty Dynamics, and Vulnerability to Poverty: An Empirical Analysis Using a Balanced Panel from Rural China. World Dev. 2016;78(1):541-53.

22. Black R, Vitora C, Walker S, Bhutta Z, Christian P, de Onis $\mathrm{M}$, et al. Maternal and child undernutrition and overweight in low-income and middle-income countries. Lancet.
2013;382(9890):427-51.

23. Alkire S. Global multidimensional poverty index. Pak Dev Rev. 2015;54(4 Part 1):287-99.

24. Adams JRH, Cuecuecha A, Page J. Remittances, consumption and investment in Ghana. Policy Research working paper; no. WPS 4515 Washington, D.C. : World Bank Group. 2008.

25. Kabubo-Mariara J, Ndenge GK, Mwabu DK. Determinants of children's nutritional status in Kenya: Evidence from Demographic and Health Surveys. J Afr Econ. 2009;18(3):363-87.

26. Ijarotimi OS. Determinants of Childhood Malnutrition and Consequences in Developing Countries. Curr Nutr Rep. 2013;2(1):129-33.

27. Reis M. Food insecurity and the relationship between household income and children's health and nutrition in Brazil. Health Econ. 2012;21(4):405-27.

28. Saaka M, Osman SM. Does Household Food Insecurity Affect the Nutritional Status of Preschool Children Aged 636 Months? Int J Popul Res. 2013;2013(Article ID 304169):1-12.

29. Borja JB, Amarra S. The impact of early nutrition on health: Key findings from the cebu longitudinal health and nutrition survey. Malays J Nutr. 2013;19(1):1-8.

30. Jr. JSC, Martinez FE. Nutritional dilemmas in extremely low birth weight infants and their effects on childhood, adolescence and adulthood. J Pediatr (Rio J). 2007;81(Suppl.1):33-42.

31. Carlson GJ, Kordas K, Murray-Kolb LE. Associations between women's autonomy and child nutritional status: A review of the literature. Matern Child Nutr. 2015;11(4):45282.

32. National Institute of Statistics of Rwanda. Integrated Household Living Conditions Survey 5 (EICV 5): Rwanda Poverty Profile. Report. 2018. 